
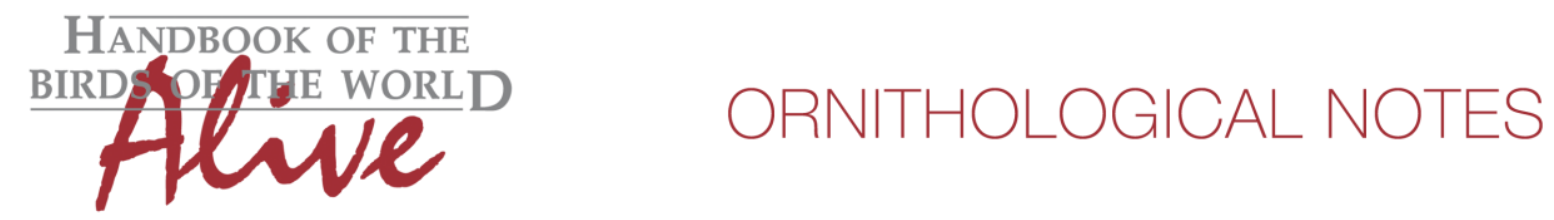

\title{
Notes on the vocalizations of Northern Fantail (Rhipidura rufiventris)
}

Peter Boesman

In the following we briefly analyze and compare voice of the different races of Northern Fantail (Rhipidura rufiventris). We also try to quantify the extent of any vocal differences using the criteria proposed by Tobias et al. (2010), as a support for taxonomic review.

We have made use of sound recordings available on-line from Xeno Canto (XC) and Macaulay Library (ML).

With twenty subspecies, many confined to single islands, this is obviously a very complex group, to say the least. This note is therefore rather a preliminary analysis, based on available recordings, which per race are often just a few or less.

An overview of vocalizations per race (some already grouped):

\section{R.r. rufiventris (incl. pallidiceps)(Timor Fantail)}

\section{rufiventris}
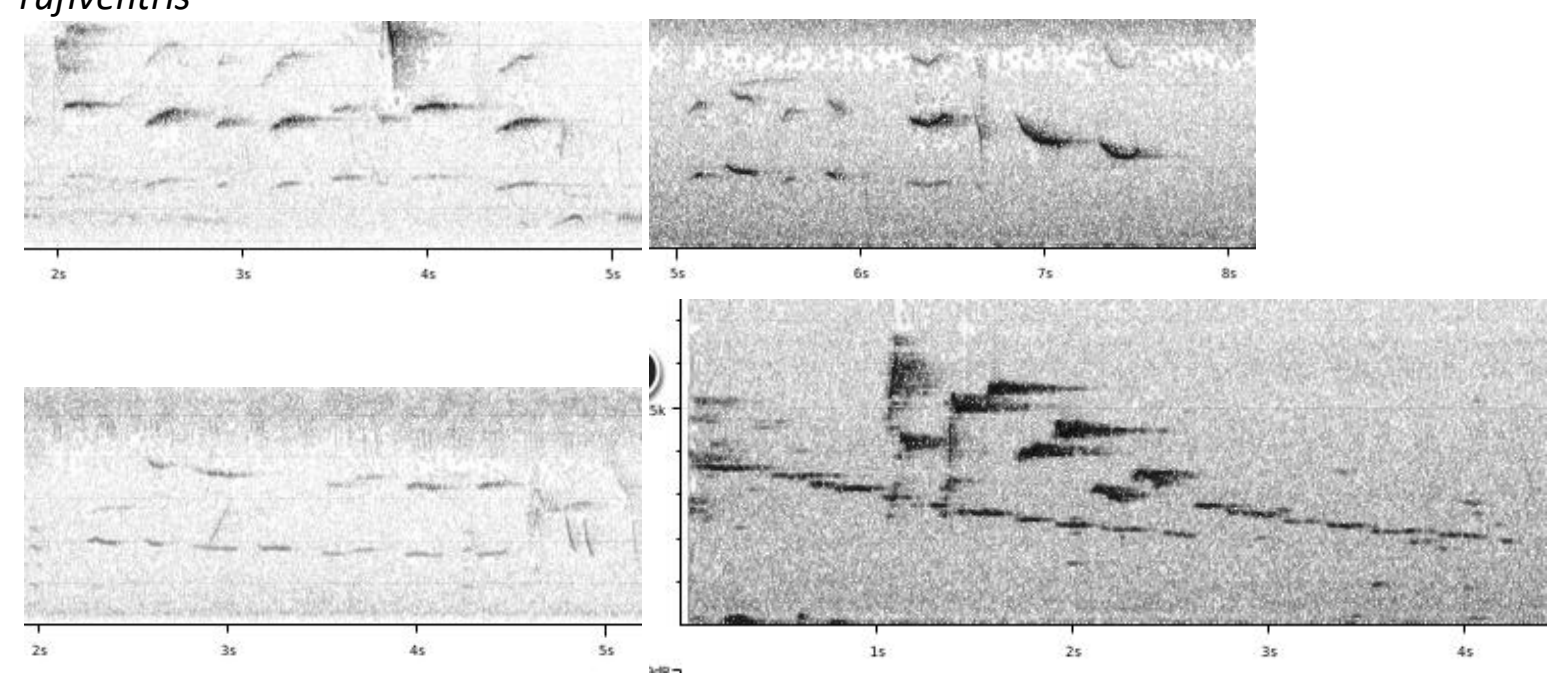

pallidiceps

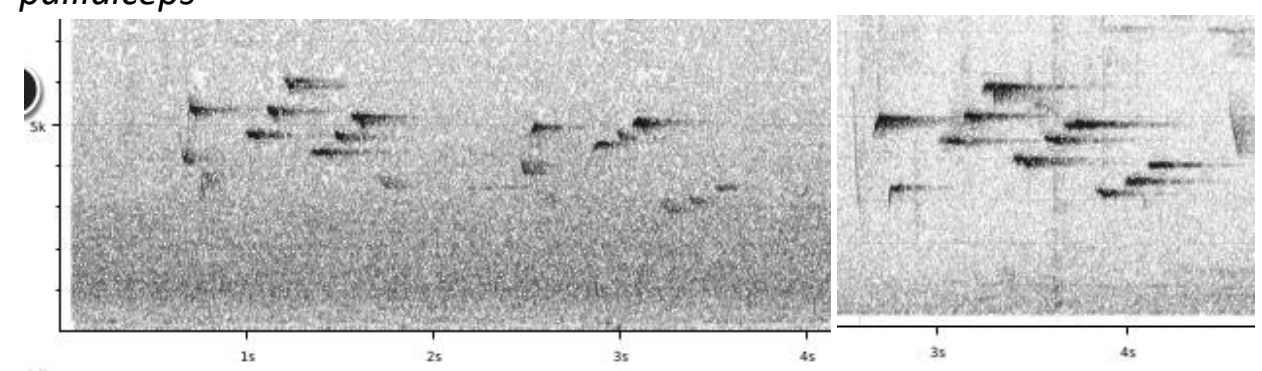

3 of 4 recordings from Timor (rufiventris) are very similar, but another recording is very different and matches all recordings from Wetar (pallidiceps). This suggests there are two song types (as in several of next races). Song type 1 is a series of about 6-10 loosely-delivered plaintive slightly nasal whistles. Song type 2 is a series of short whistles with a clear pattern: typically 3 notes ascending, followed by next three starting at lower pitch and again (typically three times). 


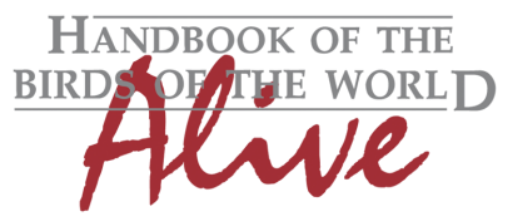

\section{ORNITHOLOGICAL NOTES}

\section{R.r. hoedti (Banda Fantail)}

\section{Song type 1:}

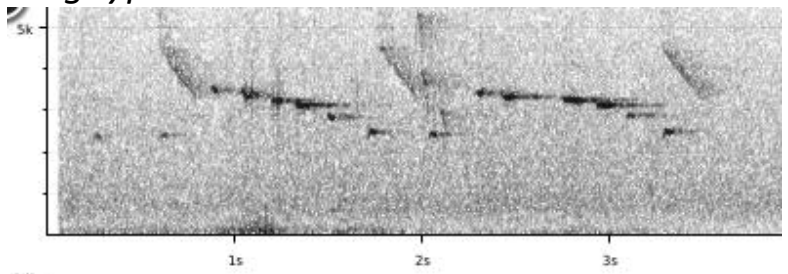

Song type 2:

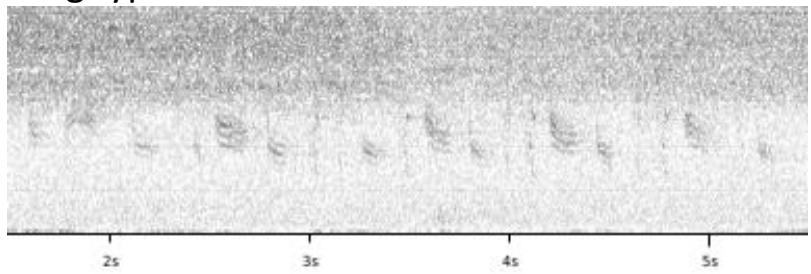

Song type 1 is a descending series of about 4-6 short sweet notes. Song type 2 is presumably a duet, a nervous rhythmic alternation of buzzy notes.

\section{R.r. tenkatei (Roti Fantail)}

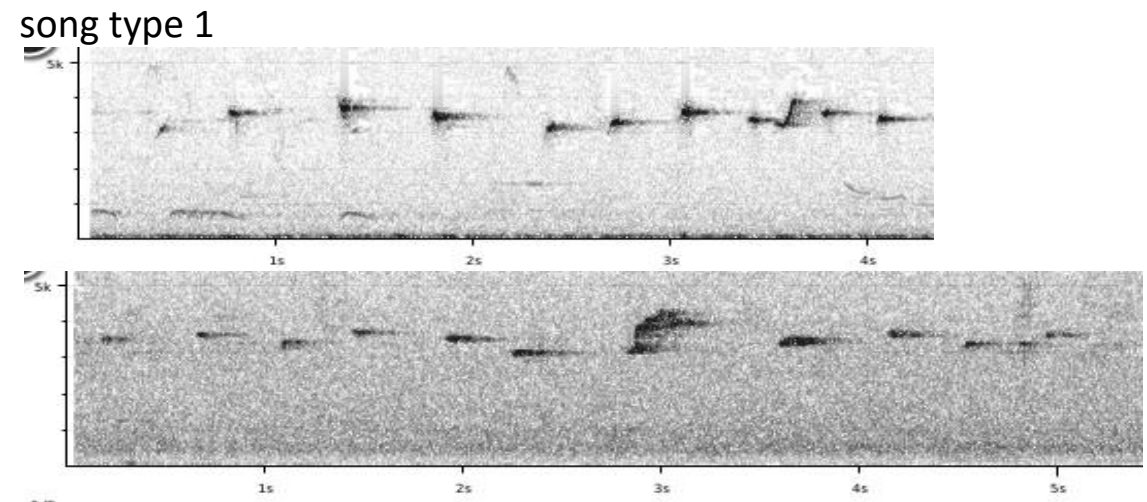

song type 2 (duet)

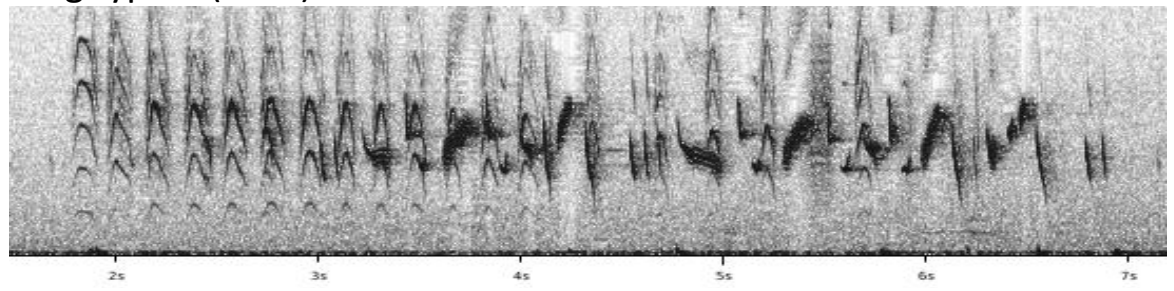

Song type 1 is a series of about 10 short notes, only slightly going up and down in pitch. Song type 2 is presumably a duet, initiated with nasal notes and followed by a medley of buzzy, burry and more melodious notes.

\section{R.r. bouruensis (Buru Fantail)}

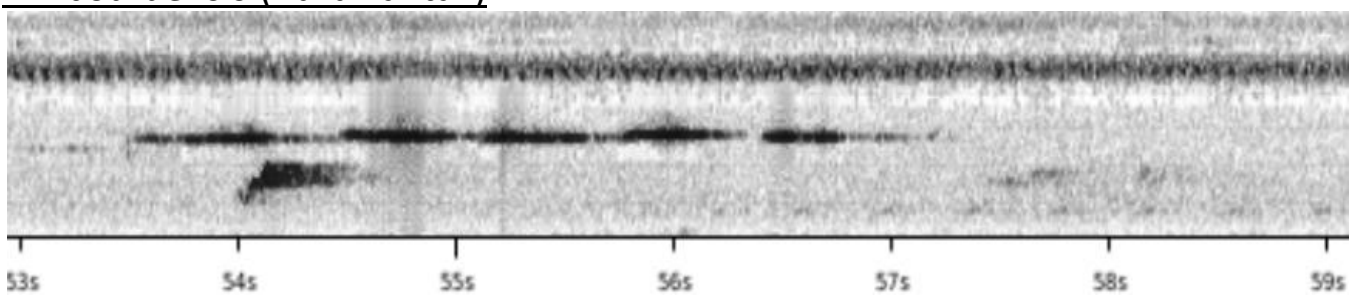

Song is a series of about 4-6 drawn-out flat-pitched notes, first note slightly lower-pitched than next ones. 


\section{HANDBOOK OF THE \\ BIRDSPF,THE WORLD \\ Aluve}

\section{ORNITHOLOGICAL NOTES}

\section{R.r. cinerea (Seram Fantail)}

No recordings available

\section{$\underline{\text { R.r. obiensis (Obi Fantail) }}$}

\section{Song type 1:}
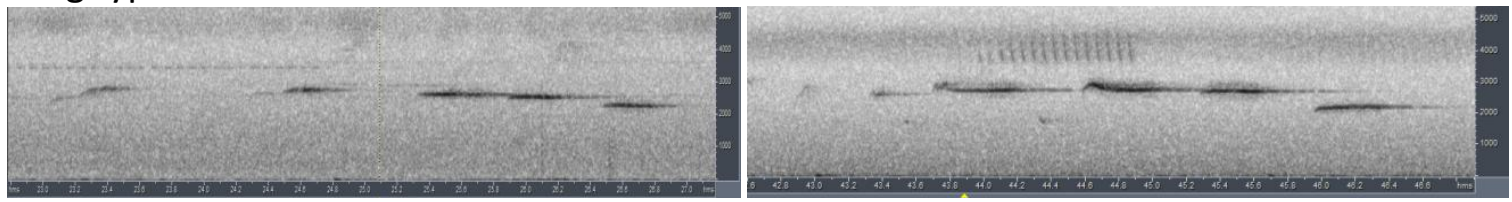

Song type 2:

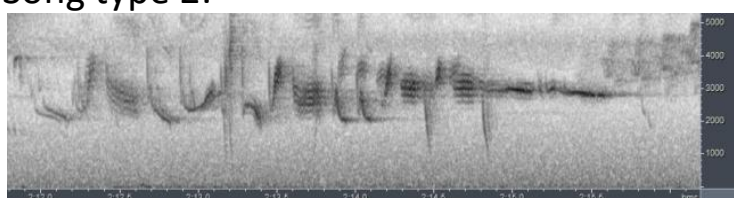

Song type 1 is a series of about 6 drawn-out flat-pitched melodious whistles at about the same pitch, the last one distinctly lower-pitched.

Song type 2 is an excited medley of buzzy and more melodious notes

\section{R.r. assimilis (Kai Fantail)}

Only recording available of presumably a call:

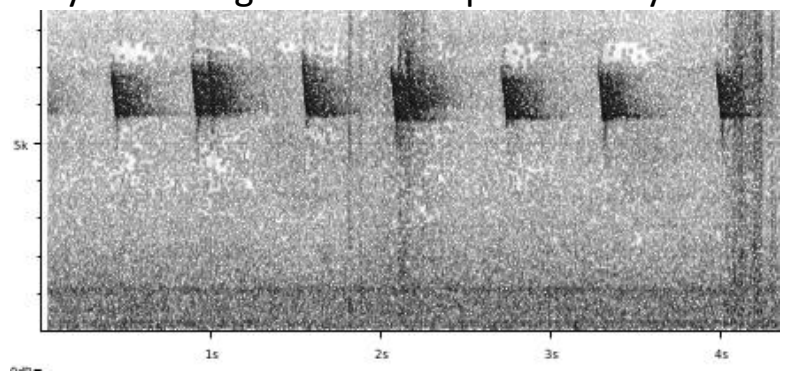

\section{R.r. gularis and vidua (New Guinea Fantail)}

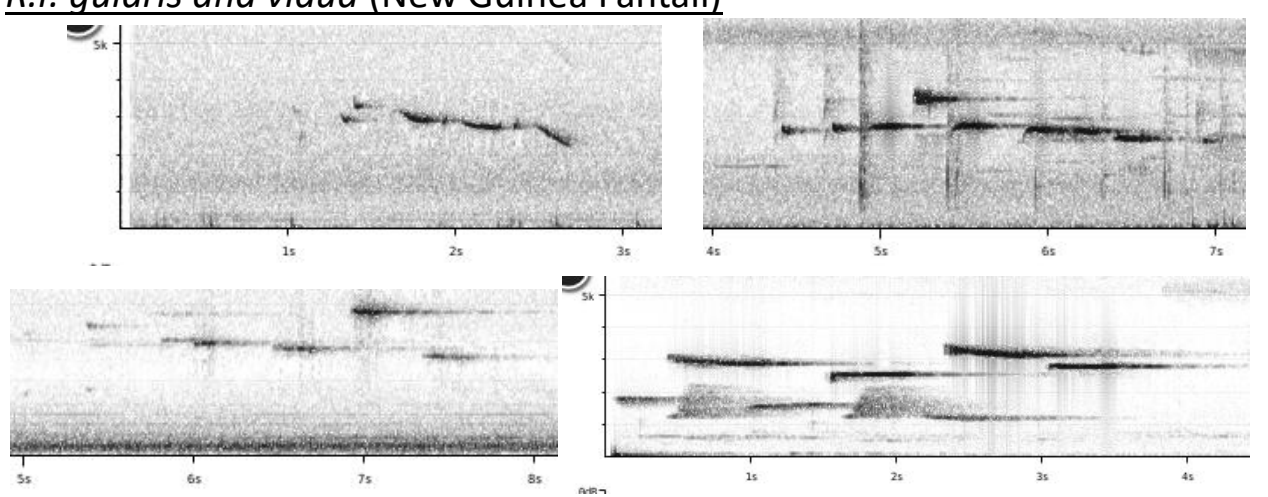

A short phrase of about 4-6 melodious whistles, typically 2nd or 3rd note higher-pitched and last note lowest pitch. A single recording, XC23205, last sonogram depicted above, is different with flat-pitched drawn-out notes, and we can't exclude a misidentification. 


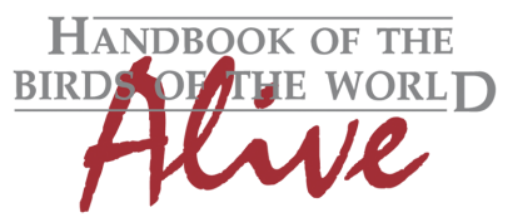

\section{ORNITHOLOGICAL NOTES}

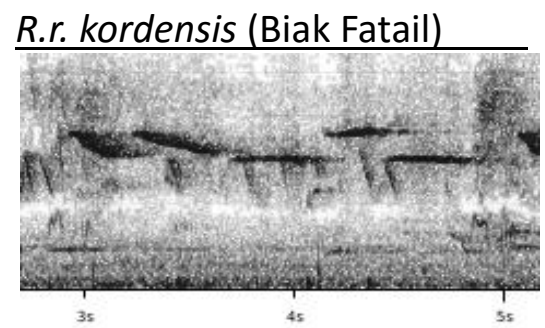

A series of about 4-5 fairly long, typically gradually descending whistles

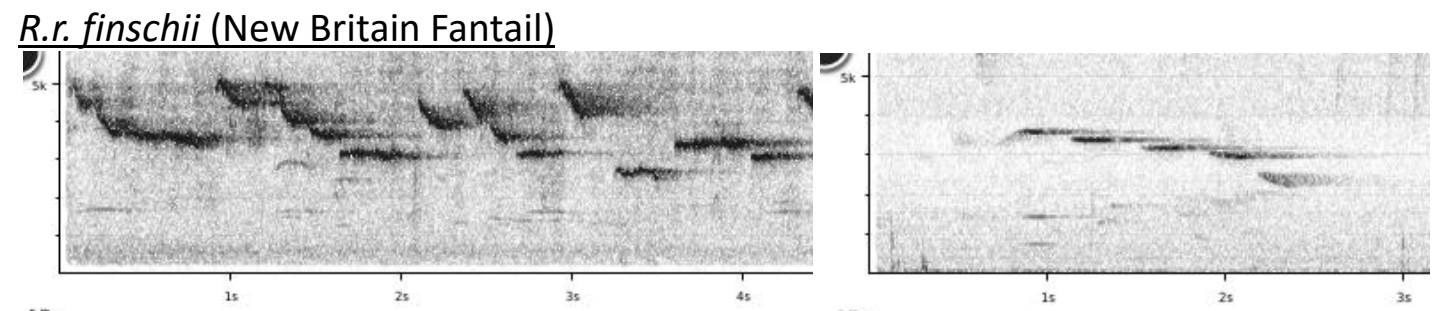

A series of about 4-6 fairly short melodious whistles which descend in pitch towards the end, sometimes in long series.

\section{$\underline{\text { R.r.setosa (New Ireland Fantail) }}$}

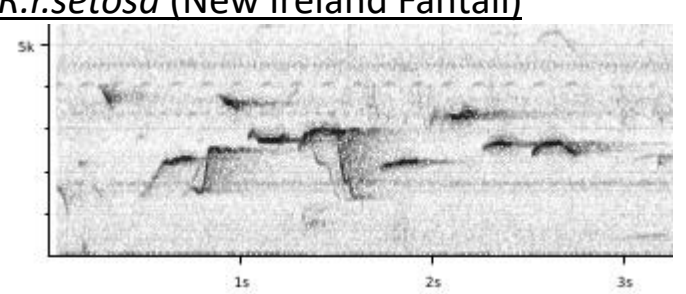

A series of sweet short whistles apparently randomly going up and down in pitch

\section{R.r. niveiventris (Admiralty Fantail)}

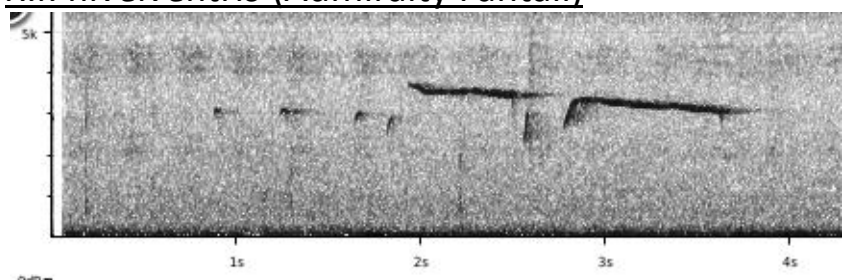

Two drawn-out flat-pitched whistles, the second slightly lower-pitched, and apparently preceded by a few very short notes.

\section{R.r. isura (Australian Fantail)}

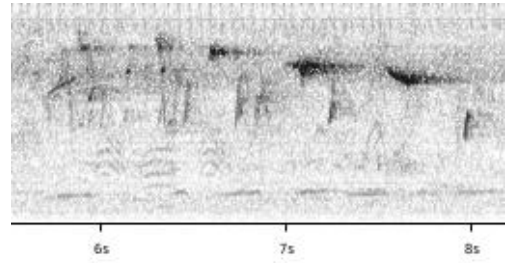



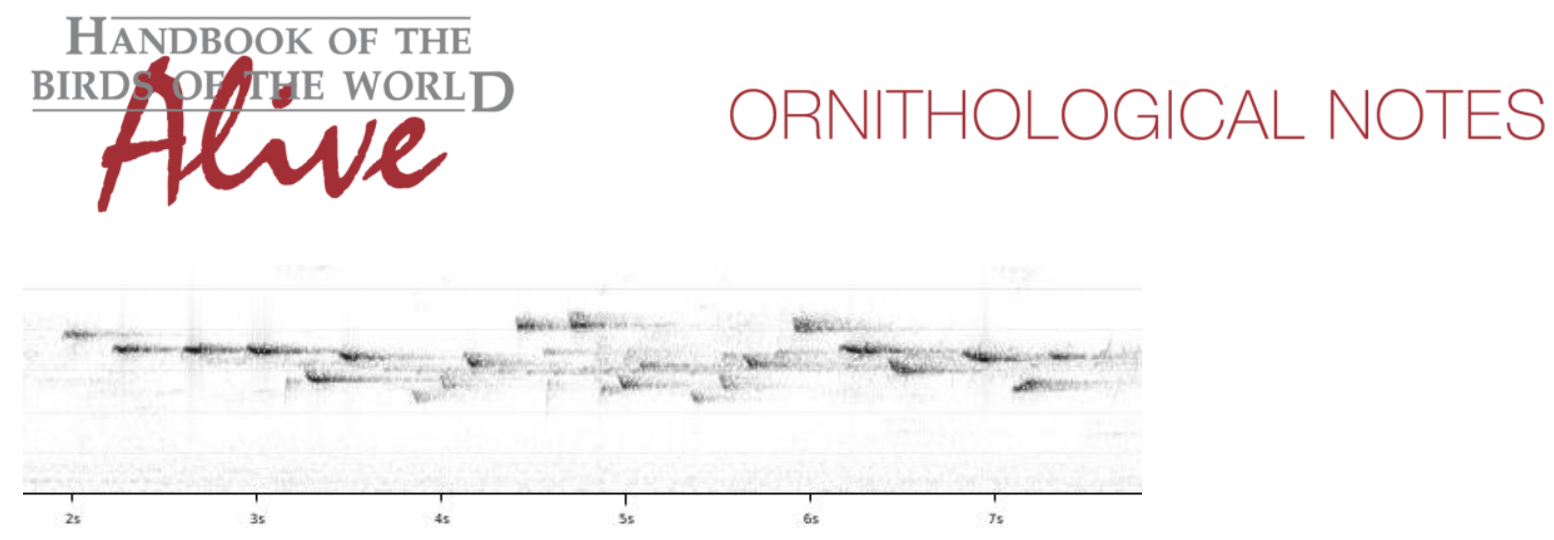

A series of short melodious whistles, either descending in pitch or randomly going up and down in pitch.

Of the Indonesian races, Buru and Obi Fantail seem to have a similar song with long notes.

The song over the large territory of New Guinea (gularis/vidua) is quite variable (and if ID of XC23205 is correct song includes both the type of 'short notes' and 'long notes'). Vocally there seems little reason not to merge with isura from $N$ Australia (although the latter possibly slightly higher-pitched).

The Biak Fantail seems to have a song of some 5 long notes, which would set it apart from the New Guinea recordings (if it weren't for that single recording from N W Papua which has long notes (XC23205)).

The New Britain Fantail (finschii) has a song of short notes which are predominantly a descending series. This could be seen as a slight differentiation from New Guinea Fantail.

The New Ireland Fantail (setosa) then again has a rather ad random up and down series of rather mellow whistles, which sets it apart from New Britain and New Guinea Fantail.

And finally, the Admiralty Fantail (niveiventris) $(n=1)$ has again a very distinct voice with a few staccato notes followed by 2 long whistles.

All this is plagued by some variability in the song of each race, the possibility of more than one song type, and the very limited number of recordings per race...

We could summarize and quantify the vocal difference of the 13 groups in a table giving a very rough and estimated score based on the few recordings we have available:

\begin{tabular}{|c|c|c|c|c|c|c|c|c|c|c|c|c|c|c|}
\hline & & 1 & 2 & 3 & 4 & 5 & 6 & 7 & 8 & 9 & 10 & 11 & 12 & 13 \\
\hline & & Timor & Banda & Roti & Buru & Seram & Obi & Kai & N G & NBrit & N Ire & Adm & Austr & Biak \\
\hline & Timor Fantail R.r. rufiventris & - & 3 & 4 & 6 & ?? & 6 & ?? & 3 & 3 & 3 & 6 & 3 & 5 \\
\hline & Banda Fantail R.r. hoedti & & - & 4 & 5 & ?? & 5 & ?? & 3 & 2 & 4 & 6 & 2 & 5 \\
\hline & Roti Fantail R.r. tenkatei & & & - & 6 & ?? & 6 & ?? & 3 & 4 & 4 & 6 & 3 & 6 \\
\hline & Buru Fantail R.r. bouruensis & & & & - & ?? & 1 & ?? & 3 & 5 & 6 & 4 & 5 & 2 \\
\hline & Seram Fantail R.r. cinerea & & & & & - & ?? & ?? & ?? & ?? & ?? & ?? & ?? & ?? \\
\hline & Obi Fantail R.r. obiensis & & & & & & - & ?? & 3 & 5 & 6 & 4 & 4 & 2 \\
\hline & 7 Kai Fantail R.r. assimilis & & & & & & & - & ?? & ?? & ?? & ?? & ?? & ?? \\
\hline & 3 New Guinea Fantail R.r. gularis/vidua & & & & & & & & - & 2 & 3 & 5 & 1 & 2 \\
\hline & New Britain Fantail R.r.finschii & & & & & & & & & - & 2 & 5 & 2 & 4 \\
\hline 10 & New Ireland Fantail R.r.setosa & & & & & & & & & & - & 6 & 3 & 5 \\
\hline 11 & Admiralty Fantail R.r.niveiventris & & & & & & & & & & & - & 6 & 2 \\
\hline & Australian Fantail R.r.isura & & & & & & & & & & & & - & 4 \\
\hline & 3 Biak Fantail Rhipidura kordensis & & & & & & & & & & & & & - \\
\hline
\end{tabular}



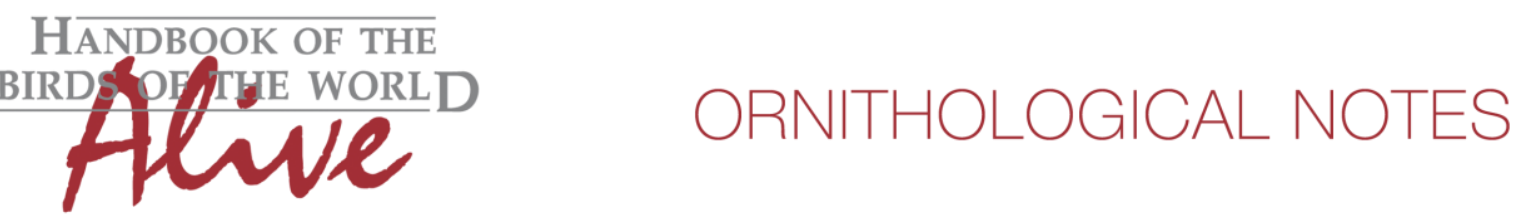

There are clearly more recordings needed to further complete this picture.

This note was finalized on 1st March 2016, using sound recordings available on-line at that moment. We would like to thank in particular the many sound recordists who placed their recordings for this species on XC and ML: Patrik Åberg, Mark Anderson, Mike Catsis, John Dumbacher, David Gibbs, Phil Gregory, Emma Greig, Frank Lambert, Linda Macaulay, Hans Matheve, John Mittermeier, John V Moore, Mike Nelson, Mark Robbins, Andrew Spencer, Colin Trainor, Bas Van Balen, Philippe Verbelen, George Wagner and Sam Woods.

\section{References}

Tobias, J.A., Seddon, N., Spottiswoode, C.N., Pilgrim, J.D., Fishpool, L.D.C. \& Collar, N.J. (2010). Quantitative criteria for species delimitation. Ibis 152(4): 724-746.

\section{Recommended citation}

Boesman, P. (2016). Notes on the vocalizations of Northern Fantail (Rhipidura rufiventris). HBW Alive Ornithological Note 186. In: Handbook of the Birds of the World Alive. Lynx Edicions, Barcelona. (retrieved from http://www.hbw.com/node/932126 on 25 August 2016). 